\title{
Recognition and stigma of prescription drug abuse disorder: personal and community determinants
}

\author{
Robert Shupp ${ }^{1^{*}}$ (D), Scott Loveridge ${ }^{2}$, Mark Skidmore ${ }^{3}$, Brandn Green ${ }^{4}$ and Don Albrecht ${ }^{5}$
}

\begin{abstract}
Background: Prescription drug abuse (PDA) disorders continue to contribute to the current American opioid crisis. Within this context, our study seeks to improve understanding about stigma associated with, and symptom recognition of, prescription drug abuse.

Aims: Model the stigma and symptom recognition of PDA in the general population.

Methods: A randomized, nation-wide, online, vignette-focused survey of the general public $(N=631)$ was implemented with an oversample for rural counties. Logit estimation was used for analysis, with regional and county-level sociodemographic variables as controls.

Results: Individual respondents that self-identify as having or having had "a prescription drug abuse issue" were less likely to correctly identify the condition and were 4 times more likely to exhibit stigma. Male respondents were approximately half as likely to correctly identify PDA as female respondents while older respondents (55+) were more likely to correctly identify PDA, relative to those aged 35-54. Being both male and younger was associated with slightly more stigma, in that they were less likely to disagree with the stigma statement.

Conclusions: In light of the continued risks that individuals with PDA behaviors face in potentially transitioning to illicit opioid use, the findings of this survey suggested a continued need for public education and outreach. Of particular note is the perspective of those who have self-identified with the condition, as this population faces the largest risks of adverse health outcomes from illicit drug use within the survey respondents.
\end{abstract}

Keywords: Prescription drug, Opioid, Stigma, Recognition, Survey

\section{Background}

Prescription drug misuse is a critical public health issue in the United States. In 2015, prescription drug misuse accounted for 52,404 deaths, $63.1 \%$ of which involved opioids [1]. Addressing the opioid crisis is a current national priority, with leading federal agencies and the Office of the President providing extensive funding and support for increasing treatment access and the use of

\footnotetext{
* Correspondence: shupprob@msu.edu

1 Department of Agricultural, Food and Resource Economics, Michigan State University, East Lansing, MI 48824, USA

Full list of author information is available at the end of the article
}

evidence-based practices. Within the context of this rapid expansion of treatment services, questions remain about the general level of knowledge about PDA and the potential influence stigma about PDA has on the pursuit of treatment or participation in prevention programming efforts $[2,3]$. In what follows we rely on the Mayo Clinic definition of PDA [4], the Mental Health First Aid definitions of recognition and Griffiths, Christensen, and Jorm [5] for stigma.

The sequence from misuse of prescription drugs to illicit drug use has been identified as a key pathway to addiction that has contributed to the opioid overdose

(c) The Author(s). 2020 Open Access This article is licensed under a Creative Commons Attribution 4.0 International License, which permits use, sharing, adaptation, distribution and reproduction in any medium or format, as long as you give appropriate credit to the original author(s) and the source, provide a link to the Creative Commons licence, and indicate if changes were made. The images or other third party material in this article are included in the article's Creative Commons licence, unless indicated otherwise in a credit line to the material. If material is not included in the article's Creative Commons licence and your intended use is not permitted by statutory regulation or exceeds the permitted use, you will need to obtain permission directly from the copyright holder. To view a copy of this licence, visit http://creativecommons.org/licenses/by/4.0/ The Creative Commons Public Domain Dedication waiver (http://creativecommons.org/publicdomain/zero/1.0/) applies to the data made available in this article, unless otherwise stated in a credit line to the data. 
crisis [6]. Raising public knowledge and reducing stigma about PDA can also improve health outcomes and reduce substance misuse [7]. In this paper, the stigma associated with PDA and the recognition of PDA among family and friends are examined to elucidate how individual-level interventions aimed at stigma reduction and PDA recognition may also contribute to turning back the tide of opioid overdoses.

Recognition of PDA in the early stages of its development may help the individual begin to take appropriate remedies before the condition is fully developed [8]. Furthermore, recognizing the condition as a disease to be treated rather than simply a problem of personal character could help individuals seek treatment more quickly [9]. Since the incidence of PDA varies by place, an important strategy for addressing the challenge of PDA is to explore the not only individual, but also community-level factors associated with recognition and stigmatization. In short, a better understanding of the personal and community characteristics associated with PDA recognition and stigma can assist in design of programs to combat the opioid crisis.

To study the statistical relationships of recognition and stigma in the context of PDA, we used a survey approach. Specifically, we implemented a national survey to identify respondent and community characteristics that increase the probability of recognizing and stigmatizing the condition of PDA. Over 30\% of respondents could not correctly identify the condition associated with the vignette that described an individual with symptoms/behaviors commonly associated with PDA. With respect to PDA stigma, correct identification of the condition is strongly associated with less agreement with a stigmatizing statement about the condition. In addition, respondent characteristics such as age and education are predictors of both recognition and stigma as are several county-level variables. The results help inform how to target PDA prevention efforts. Results also imply that mental health providers might be an important ally in future efforts to improve recognition rates and address stigma.

\section{Methods}

The prescription drug abuse survey took place in July, 2016. The IRB was approved by Michigan State University Human Research Protection Program on October 1, 2014. Survey Sample International (SSI) was used to obtain a nationally representative respondent pool as well as a rural over-draw. The SSI company maintains a large opt-in panel of survey respondents balanced on age, gender, income and region. Opt-in panels are increasingly accepted in survey work as response rates from phone and mail surveys are dwindling. Opt-in panels seem to produce results comparable to robust traditional surveys, but at lower expense [10]. We requested additional respondents from rural areas to investigate the role that rural areas may play in recognition and stigma as, seemingly, in contrast to prior outbreaks of drug abuse epidemics, there is anecdotal evidence of PDA higher incidence in rural areas. Additional rural respondents were drawn from randomly selected rural counties as defined by the 2013 USDA Rural Urban Continuum Codes (counties with a code of 7, 8 and 9) and was also balanced on age, gender and income to the extent possible. A national pretest was used to help finalize the survey design.

The survey was opened to the SSI panel until the required number of responses was obtained from each category (gender, income, region, etc.) required for a balanced response set; thus there is no response rate as classically defined in survey research. The survey instrument presented respondents with a vignette that described an individual with symptoms/behaviors commonly associated with PDA. To account for possible gender effects half the respondents (approximately 250 national draw and 63 rural draw) received a vignette about a woman (Michelle) while the other half received a vignette about a man (Michael). Generally, the vignette is based on those found in Jorm et al. [11]. The Michael version of the vignette used in the survey follows.

Vignette: Michael is 30 years old. He went to see his doctor after experiencing a work-related injury and the doctor prescribed a painkiller, hydrocodone (brand names: Vicodin, Norco, Lortab), for Michael to take. $\mathrm{He}$ started taking the painkiller as instructed by the doctor but felt like it was not enough to control his pain and started taking an extra pill every day. After a follow-up visit, the doctor told Michael that his injury had healed and that he should stop taking the painkiller, but he continued taking it until he ran out. At that point, he felt like he needed more of the painkiller and went to a new doctor to get a new prescription.

A total of 631 respondents completed the survey. After reading the vignette, the respondent was asked a series of questions about what might be wrong with the person described in the vignette, how that person might be helped, and a series of questions designed to measure the respondent's stigma regarding people like the one in the vignette. We adapted stigma questions from Griffiths, Christensen, and Jorm [5] to reflect the appropriate issue and to better fit our US context, as their work originated in Australia. Given that it is likely that personal experience in dealing with prescription drug use disorders, either in oneself or a family member, will impact recognition and/or stigma responses, subsequent to the vignette and recognition, stigma, and help-seeking questions, respondents were asked about their own and family member/close friend history of PDA. In addition, standard sociodemographic questions were included to be used to further explore the determinants of recognition and stigma. All results, except the recognition and stigma response proportions, are presented in 
Table 1 Summary statistics for prescription drug abuse regression variables

\begin{tabular}{llllll}
\hline Variables & Min. & Max. & Mean & Std. Dev. & 2017 American Community Survey Estimates \\
\hline Own Prescription Drug Abuse: Yes & 0 & 1 & 0.138 & 0.345 & - \\
Family/Friend Prescription Drug Abuse & 0 & 1 & 0.338 & 0.473 & - \\
Male & 0 & 1 & 0.425 & 0.495 & 0.487 \\
White & 0 & 1 & 0.849 & 0.358 & $0.730^{b}$ \\
ID: Prescription Drug Abuse & 0 & 1 & 0.678 & 0.468 & - \\
Age 18-34 & 0 & 1 & 0.323 & 0.468 & $0.243^{c}$ \\
Age 55+ & 0 & 1 & 0.319 & 0.466 & 0.276 \\
Income < \$25K & 0 & 1 & 0.200 & 0.400 & 0.214 \\
Income \$25-50 K & 0 & 1 & 0.247 & 0.432 & 0.225 \\
Income \$75-100 K & 0 & 1 & 0.171 & 0.377 & 0.123 \\
Income \$100 K+ & 0 & 1 & 0.190 & 0.393 & 0.262 \\
Education: some college & 0 & 1 & 0.307 & 0.462 & 0.208 \\
Education: college degree & 0 & 1 & 0.273 & 0.446 & $0.274^{d}$ \\
Education: college above bachelors & 0 & 1 & 0.166 & 0.373 & 0.118 \\
Name: Michelle & 0 & 1 & 0.502 & 0.500 & - \\
Northeast & 0 & 1 & 0.176 & 0.381 & 0.172 \\
Midwest & 0 & 1 & 0.244 & 0.430 & 0.210 \\
West & 0 & 1 & 0.225 & 0.418 & 0.238
\end{tabular}

${ }^{a}$ Source: American Fact Finder. American Community Survey (ACS) 2017

${ }^{b}$ White race alone. Proportion white race and other races in ACS is 0.757

'Census reports 15-19 age bracket. Two-fifths of that age bracket were added to the 20 to 34 age brackets to estimate the ACS 18-34 proportion

${ }^{\mathrm{d}}$ Combined bachelors and associates degrees

unweighted format due to our use of socio-economic controls used by SSI to recruit a balanced sample. While we constructed weights for the response proportions, using weights in a regression that also uses the variables used to construct the weights would introduce bias.

In the following analysis, the primary data from the survey is matched with regional level indicator variables as well as a selection of county-level secondary data drawn from the Robert Wood Johnson Foundation-funded County Health Rankings project at the University of Wisconsin. While the University of Wisconsin data provides counts of mental health services providers, there are many missing values so mental health coverage quartiles, which are more complete, are used instead of counts. Finally, consistent with observations by Cerdá et al. [12] we proxy state-level community health norms with each state's position with respect to loosening of restrictions on marijuana. We draw the state's legalization position from an inventory produced by Governing magazine [13].

Analysis of recognition uses multilevel mixed-effects logit estimation with respondent, regional and countylevel sociodemographic variables as controls. Analysis of the responses to stigma questions is conducted using a generalized linear multilevel multinomial logit estimation procedure, again using controls. We selected multinomial logit for analysis of the stigma data because it allows the response categories to be unordered, and our
Table 2 Summary Statistics for Prescription Drug Abuse Regression Variables (County-Level Public Data)

\begin{tabular}{lllll}
\hline Variables & Min. & Max. & Mean & Std. Dev. \\
\hline Rural & 0 & 1 & 0.201 & 0.401 \\
Unemployment & 1 & 17 & 8.394 & 2.571 \\
Association Rate & 0.165 & 4.741 & 1.091 & 0.543 \\
Percent fair or poor health & 7 & 36 & 16.312 & 4.486 \\
Percent access to exercise & 0 & 100 & 79.198 & 22.972 \\
Percent uninsured & 3 & 35 & 16.824 & 5.739 \\
Percent frequent physical distress & 7 & 20 & 11.333 & 2.149 \\
Percent frequent mental distress & 7 & 17 & 11.179 & 1.683 \\
Percent lack of sleep & 23 & 45 & 33.876 & 3.660 \\
Percent physically inactive & 9 & 41 & 23.762 & 5.755 \\
2nd Quartile & 0 & 1 & 0.263 & 0.441 \\
3rd Quartile & 0 & 1 & 0.171 & 0.377 \\
4th Quartile & 0 & 1 & 0.119 & 0.324 \\
Percent excessive drinking & 9 & 26 & 17.643 & 2.969 \\
Percent alcohol driving deaths & 0 & 100 & 30.450 & 11.033 \\
Violent crime rate & 0 & 1190 & 368.210 & 230.012 \\
Percent child poverty & 4 & 51 & 22.631 & 8.228 \\
Legalized Marijuana State Law & 0 & 1 & 0.661 & 0.474 \\
\hline
\end{tabular}


Table 3 What is wrong with X? Multiple response question (percentages)

\begin{tabular}{ll}
\hline Survey Response Option & Proportion \\
\hline Depression & 0.13 \\
Nervous Breakdown & 0.04 \\
Schizophrenia/Paranoid Schizophrenia & 0.01 \\
Mental Ilness & 0.05 \\
Psychological/Emotional Problems & 0.09 \\
Stress & 0.10 \\
Has a Problem & 0.29 \\
Cancer & 0.02 \\
Nothing & 0.04 \\
Other & 0.02 \\
Don't Know & 0.06 \\
Alcohol Abuse & 0.03 \\
Prescription Drug Abuse & 0.68 \\
Physical Injury & 0.09 \\
Anxiety Disorder & 0.07 \\
Number of respondents & 631 \\
\hline
\end{tabular}

survey allowed the "don't know" option in the Likerttype questions, and a priori "Don't know" is neither higher nor lower than, say, "strongly agree." The neutral "neither agree nor disagree" category was used as the base response for the stigma analysis. The strongly (dis) agree and (dis) agree categories were combined in the multinomial logit analysis to facilitate interpretation. In the multinomial logit model the log-odds of each response is expressed as follows: $\mu_{i j}=\log \frac{\pi_{i j}}{\pi_{i j}}=\alpha_{j}+x_{i}^{\prime} \beta_{j}$,

where $\alpha_{j}$ is a constant and $\beta_{j}$ is a vector of regression coefficients, for $j=1,2, \ldots, J-1$. This model is similar to the binary outcomes model except that it extends to more than two outcomes. See Aldrich and Nelson [14] for a discussion of the procedure.

\section{Results}

Tables 1 and 2 provides the summary statistics for respondent, regional and county-level sociodemographic variables. To provide a comparison with national statistics, American Community Survey data are provided in the last column of Table 1, which covers the individual-level data provided by respondents. Note that the self-reporting of prior experience with prescription drug abuse by the respondent (13.8\%) is slightly lower, but comparable to other measures. For example, a 2015 national survey by the Substance Abuse and Mental Health Services Administration (SAMHSA) suggests around $20 \%$ of those aged 12 or older have misused or abused prescription drugs at least once in their life [15]. Table 2 provides survey-level frequencies of public county or state level data matched to respondents.

To prevent respondents from not selecting the correct recognition response because they were trying to decide between two or more options, the survey question used to measure recognition allowed multiple responses (i.e., select all that apply). Despite this, while the majority of respondents selected the correct condition (PDA), a large proportion (32\% - see Table 3) did not correctly identify the problem. The three next most selected responses were 'has a problem' (29\%), 'depression' (13\%), and 'stress' (10\%). While 'has a problem' is generic enough to be true for many issues, depression and stress are often considered precursors and/or symptoms of PDA [16, 17]. Four percent of respondents thought there was nothing wrong with the person in the vignette. Figure 1 reports the percentages for each response category for the question measuring stigma - "X's problem is not a real medical illness". Twenty

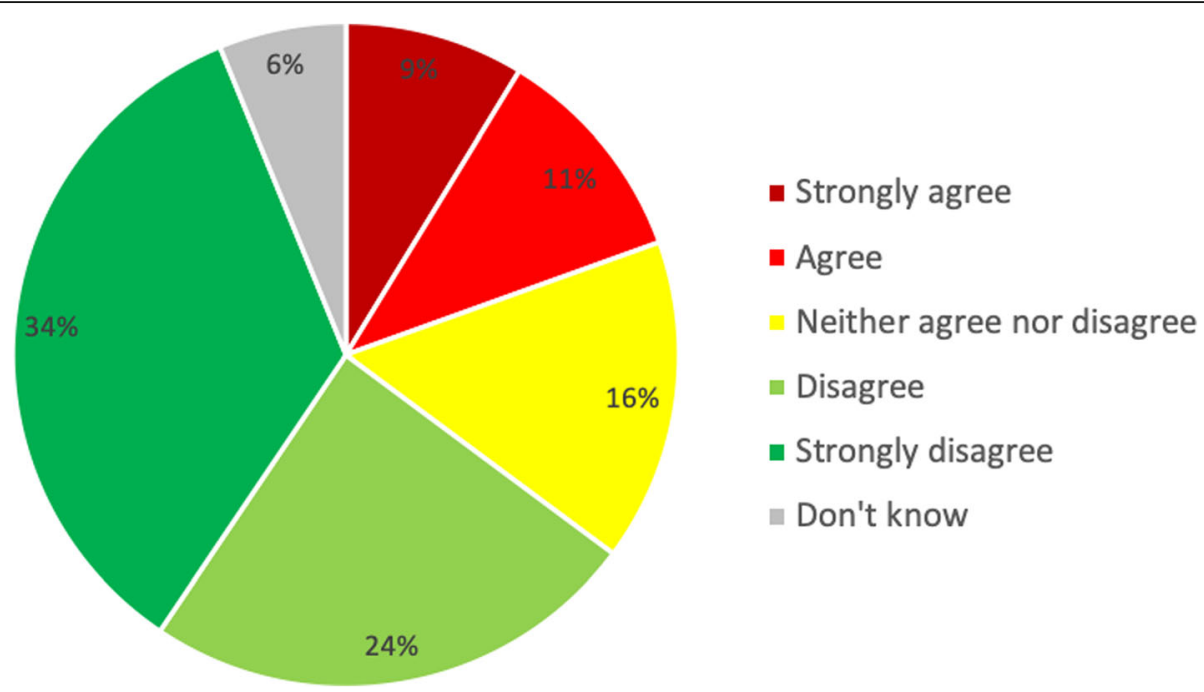

Fig. 1 Stigma - X's problem is not a real medical illness - Frequencies (percentages) 
percent of respondents indicated high levels of stigma (selected "strongly agree" or "agree"), while $58 \%$ of respondents indicated low levels or no stigma (selected "strongly disagree" or "disagree") and 16\% indicated middling levels of stigma.

\section{Recognition regression results}

Table 4 presents the results of the recognition multi-level mixed-effects logit estimations. The farthest right column $(\operatorname{Exp}(B))$ shows the influence of the associated variable on probability of selecting the correct condition ("Prescription Drug Abuse"), with values greater than (less than) one indicating an increased (decreased) probability. With regard to respondent level variables, respondents that self-identify as having or having had "a prescription drug abuse issue" are less likely to correctly identify the condition. Gender, age and education also play a significant role in PDA recognition. Male respondents are approximately half as likely to correctly identify PDA as female respondents while older $(55+)$ respondents were more likely to correctly identify the condition, relative to those aged 35-54. Relative to the base level of education (high school or less), a higher level of education consistently leads to a higher likelihood of correctly identifying PDA. However, it is only significant in the "some college" and "college degree" categories (twice as likely). Finally, the gender of the person described in the vignette (Michael or Michelle) did not appear to play a role in respondent recognition of PDA.

In terms of the regional and county-level variables, the only statistically meaningfully significant factor with regard to PDA recognition was if the respondent was from a county in the highest quartile of mental health providers per capita. ${ }^{1}$ Relative to those from counties in the lowest quartile respondents in the highest quartile counties were less than half as likely to correctly identify the condition as PDA.

\section{Stigma regression results}

For the stigma question, we report the results of a generalized linear multilevel multinomial logit estimation procedure with "neither agree nor disagree" as the base category. Table 5 presents results for "strongly agree/ agree" and "strongly disagree/disagree", while the "don't know" category results are presented in Table 6 and show that the differences between "don't know" and "neither agree nor disagree" responses are significant enough to suggest that combining the two categories for the analysis is inappropriate. ${ }^{2}$

\footnotetext{
${ }^{1}$ Meaningful in this context meaning the $\operatorname{Exp}(\mathrm{B})$ is more than slightly different than one.

${ }^{2}$ Note that for the "don't know" regression in Table 6 we report simple multinomial logit estimations (with regional controls) instead of a multilevel analysis since the multilevel version would not converge.
}

Table 4 Multilevel mixed-effects logit estimation: prescription drug abuse recognition

\begin{tabular}{|c|c|c|}
\hline & Sig. & $\operatorname{Exp}(B)$ \\
\hline \multicolumn{3}{|l|}{ Respondent Variables: } \\
\hline Own Prescription Drug Abuse & 0.000 & 0.345 \\
\hline Friend/family Prescription Drug Abuse & 0.169 & 1.411 \\
\hline Male & 0.006 & 0.541 \\
\hline White & 0.085 & 1.582 \\
\hline \multicolumn{3}{|l|}{ [Age base $=35-54]$} \\
\hline Age 18-34 & 0.060 & 0.649 \\
\hline Age 55+ & 0.000 & 2.909 \\
\hline \multicolumn{3}{|l|}{ [Respondent Income: base $=\$ 50-75)]$} \\
\hline$\$ 25 \mathrm{~K}$ or less & 0.466 & 1.299 \\
\hline$\$ 25-50 \mathrm{~K}$ & 0.492 & 1.250 \\
\hline$\$ 75-100 \mathrm{~K}$ & 0.976 & 1.010 \\
\hline$\$ 100 \mathrm{~K}+$ & 0.561 & 1.206 \\
\hline \multicolumn{3}{|l|}{ [Respondent Education: base $=\mathrm{HS}$ or less] } \\
\hline Some college & 0.018 & 2.019 \\
\hline College degree & 0.024 & 2.034 \\
\hline More than College & 0.787 & 1.099 \\
\hline \multicolumn{3}{|l|}{ [Sufferer in Vignette: base = Michael] } \\
\hline Michelle & 0.302 & 1.236 \\
\hline \multicolumn{3}{|l|}{ Regional Level Variables: } \\
\hline Northeast & 0.279 & 0.644 \\
\hline Midwest & 0.637 & 1.190 \\
\hline West & 0.655 & 1.251 \\
\hline \multicolumn{3}{|l|}{ County Level Variables: } \\
\hline Rural & 0.390 & 1.408 \\
\hline Unemployment & 0.833 & 0.986 \\
\hline Association Rate & 0.415 & 0.789 \\
\hline Percent fair or poor health & 0.829 & 0.982 \\
\hline Percent access to exercise & 0.328 & 1.008 \\
\hline Percent uninsured & 0.642 & 0.986 \\
\hline Percent frequent physical distress & 0.522 & 0.852 \\
\hline Percent frequent mental distress & 0.098 & 1.353 \\
\hline Percent lack of sleep & 0.238 & 0.939 \\
\hline Percent physically inactive & 0.069 & 1.083 \\
\hline \multicolumn{3}{|c|}{ [County Quartile Mental Health Providers Per Capita: base = lowest] } \\
\hline 2nd Quartile & 0.309 & 0.749 \\
\hline 3rd Quartile & 0.216 & 0.656 \\
\hline 4th Quartile & 0.027 & 0.421 \\
\hline Percent excessive drinking & 0.458 & 0.952 \\
\hline Percent alcohol driving deaths & 0.169 & 1.015 \\
\hline Violent crime rate & 0.179 & 0.999 \\
\hline Percent child poverty & 0.739 & 0.990 \\
\hline Legalized Marijuana State Law & 0.900 & 1.043 \\
\hline Constant & 0.960 & 1.155 \\
\hline Number of observations & & 590 \\
\hline Number of groups (counties with observations) & & 392 \\
\hline Log Pseudolikelihood & & -292.35 \\
\hline
\end{tabular}


Table 5 Generalized Linear Multilevel Multinomial Logit Estimation for "Not a Real Medical Illness" Measure of Prescription Drug Abuse Stigma (Versus Base of Neither Agree nor Disagree)

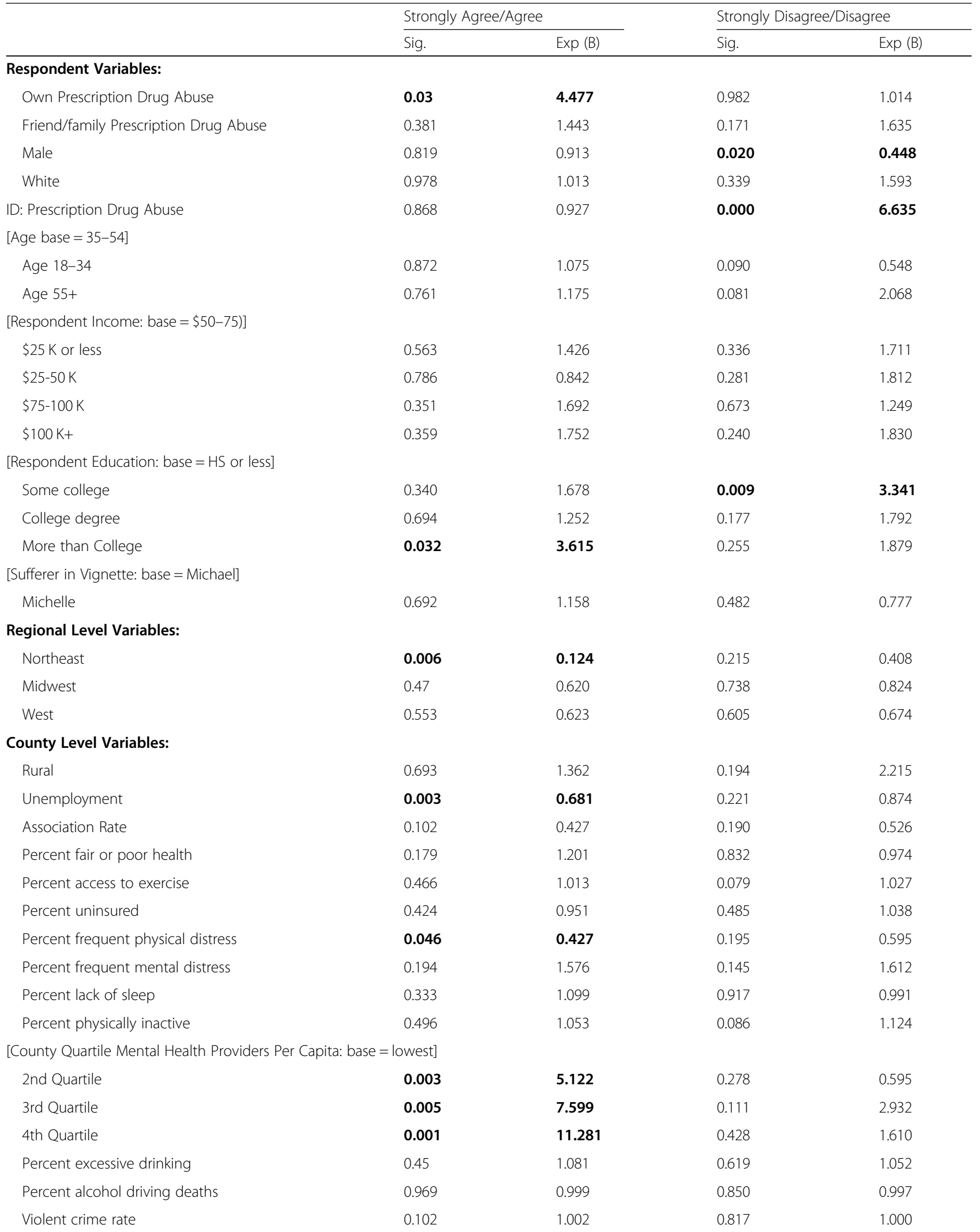


Table 5 Generalized Linear Multilevel Multinomial Logit Estimation for "Not a Real Medical IIIness" Measure of Prescription Drug Abuse Stigma (Versus Base of Neither Agree nor Disagree) (Continued)

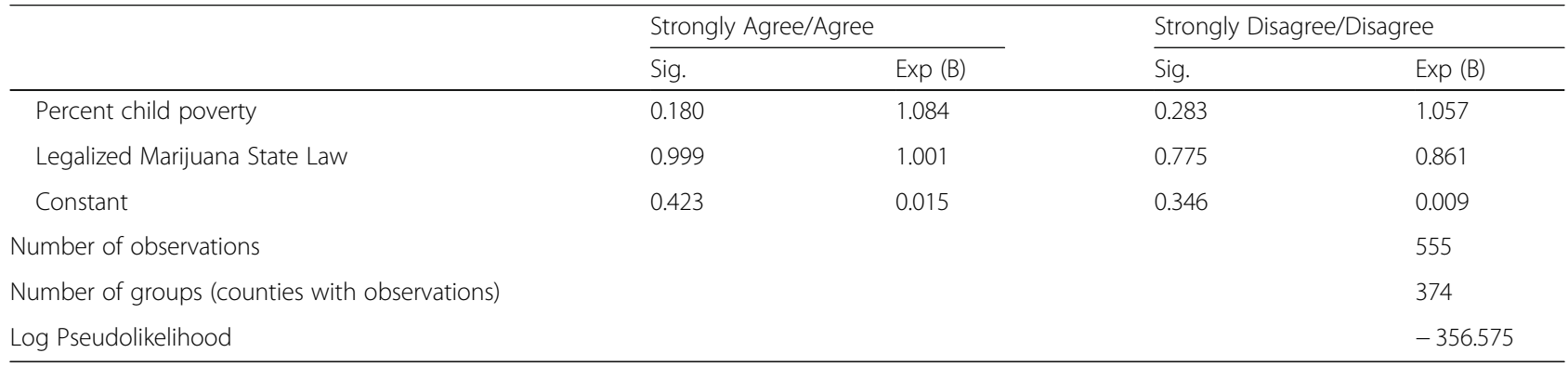

As shown in Table 5, we find that respondents who self-identify as having or having had "a prescription drug abuse issue" are about 4.5 times more likely to exhibit stigma, when stigma is measured by the question " $\mathrm{X}$ 's problem is not a real medical illness". This might seem counterintuitive but could be either a potential indicator that education of people with PDA issues is incomplete, they do not see PDA through a medical perspective, or that they feel ashamed in not being able to deal with the condition. We also find that correctly identifying the condition as PDA in the vignette is associated with much less stigma (6.6 times more likely to disagree). Being male is associated with slightly more stigma, in that they are less likely to disagree with the statement. With regard to education, relative to respondents with a high school education or less, respondents with some college were 3.3 times more likely to disagree (exhibit less stigma) while those with high levels of education (more than a bachelor's) were 3.6 times more likely to agree (exhibit more stigma). In terms of the regional and county-level variables, respondents from the Northeast region (as defined by US Census) were much less likely to agree, relative to those from the Southeast (the base region). Similarly, respondents from counties with higher levels of unemployment and higher percentages of frequent physical distress exhibited less stigma by being less likely to agree. Finally, respondents living in counties with higher ratios of mental health providers exhibited very high levels of stigma relative to those from the lowest quartile. Specifically, those in the 2nd quartile were 5 times more likely, those in the and 3rd quartile were 7.5 times more likely, while those in the 4th (highest) were more than 11 times more likely to agree or strongly agree that the condition was not a real medical illness. The strength and consistency of this last result is intriguing and may indicate a need as well as a pathway for educating the public about PDA. This result in combination with the fact that correct identification in counties with higher ratios of mental health providers was also less likely (although only significantly so in the 4th quartile), might suggest targeting prevention outreach and education about PDA within these counties and for these outreach efforts to potentially leverage the presence of mental health providers.

\section{Discussion}

Our findings indicate there may be some additional pathways to reducing PDA that could supplement current efforts. Blanco, et al. [8] has suggested that recognizing PDA in the earlier stages of development is important in reversing the condition. Our work can be used to help identify the PDA risk in the population, thereby improving the effectiveness of prevention education. While our findings indicate that the level of PDA symptom recognition in the public is relatively good, there is room for improvement. Results suggest that efforts to target limited educational resources available to teach people about this disease might focus on males under the age of 55 given that this group had more difficulty correctly identifying the condition than females and those over 55 . In our stigma model, correct identification of the problem is strongly associated with lower stigma felt towards those who might be experiencing PDA. As noted by Goodyear et al. [7], reducing stigma can help to reduce substance misuse. Thus, primary prevention efforts through education might put the most emphasis on helping the general public correctly identify PDA symptoms, rather than in attempting to reduce PDA stigma directly. While a primary focus on treating individuals and fighting availability of addictive prescription drugs such as opioids seems appropriate, an additional effort in public education towards recognizing PDA symptoms in others might assist individuals in avoiding adverse use and, when needed, select to pursue treatment due to potentially encouraging a higher proportion of users obtaining treatment services at an early stage in the progression of the disease. Similarly results show that the southeast part of the US might warrant more intensive efforts than other parts of the country.

It should be noted, however, that this study is based on data generated through one survey conducted over a relatively short period of time. We can therefore say 
Table 6 Multinomial Logit Estimation for "Not a Real Medical Illness" Stigma Response to Prescription Drug Abuse ("Don't Know" Versus Base of "Neither Agree nor Disagree")

\begin{tabular}{lll}
\hline Respondent Variables & Sig. & Exp (B) \\
\hline Own Prescription Drug Abuse & 0.158 & 0.007 \\
Friend/family Prescription Drug Abuse & 0.134 & 8.047 \\
Male & 0.462 & 0.533 \\
White & 0.558 & 1.952 \\
ID: Prescription Drug Abuse & $\mathbf{0 . 0 0 3}$ & $\mathbf{0 . 0 1 9}$
\end{tabular}

[Age base $=35-54]$

$$
\text { Age 18-34 }
$$

0.003

0.005

Age $55+$

[Respondent Income: base $=\$ 50-75)]$

$\$ 25 \mathrm{~K}$ or less
$\$ 25-50 \mathrm{~K}$
$\$ 75-100 \mathrm{~K}$
$\$ 100 \mathrm{~K}+$

$0.518 \quad 2.262$

$0.252 \quad 3.637$

$0.044 \quad 0.004$

0.074

0.023

[Respondent Education: base $=\mathrm{HS}$ or less]

$$
\begin{aligned}
& \text { Some college } \\
& \text { College degree } \\
& \text { More than College } \\
& \text { [Sufferer in Vignette: base = Michael] } \\
& \text { Michelle }
\end{aligned}
$$

Regional Level Variables

Northeast
Midwest
West

County Level Variables
Rural
Unemployment
Association Rate
Percent fair or poor health
Percent access to exercise
Percent uninsured
Percent frequent physical distress
Percent frequent mental distress
Percent lack of sleep
Percent physically inactive

[County Quartile Mental Health Providers Per Capita: base = lowest]

$\begin{array}{lll}\text { 2nd Quartile } & \mathbf{0 . 0 2 3} & \mathbf{0 . 0 2 3} \\ \text { 3rd Quartile } & 0.471 & 3.011 \\ \text { 4th Quartile } & \mathbf{0 . 0 6 4} & \mathbf{0 . 0 2 9} \\ \text { Percent excessive drinking } & 0.711 & 0.906 \\ \text { Percent alcohol driving deaths } & 0.216 & 0.933 \\ \text { Violent crime rate } & 0.549 & 0.998 \\ \text { Percent child poverty } & 0.409 & 1.136\end{array}$

Table 6 Multinomial Logit Estimation for "Not a Real Medical Illness" Stigma Response to Prescription Drug Abuse ("Don't Know" Versus Base of "Neither Agree nor Disagree") (Continued)

\begin{tabular}{lll}
\hline Respondent Variables & Sig. & Exp (B) \\
\hline Legalized Marijuana State Law & 0.198 & 7.776 \\
Constant & 0.126 & $5.37 \mathrm{e}-08$ \\
Number of observations & & 127 \\
Cox \& Snell R-squared & & 0.484 \\
Nagelkerke R-squared & & 0.700 \\
\hline
\end{tabular}

nothing of the direction or speed of trends in knowledge and stigma regarding these conditions. Furthermore, our sample, while sufficient to make statements about national conditions, is insufficient to provide estimates at the regional, state, or municipal level. It is quite likely that regional variations within states are present, and we may be missing important controls that would be evident if more data points were available. We also note that our vignette was inclusive of only one aspect of PDA and used single measure variables, suggesting that subsequent research could both include broader indices and examine substance specific stigma and recognition.

That said, one potential avenue suggested by our results for accomplishing better PDA education might be to enlist mental health service providers in delivery of general public education programs such as Mental Health First Aid. Mental health service providers have all the right knowledge sets to be effective in communicating with the public to help broaden the general awareness of PDA and the associated conditions, yet the level of service provision available in the respondent's county is not associated with better recognition of PDA or lower levels of stigma. Engaging these mental health service providers to help educate the public in these areas could help increase recognition and reduce stigma while adding to the credibility of such campaigns and could result in early interventions and increased rates of successful treatments. The efficacy of different types of targeted educational interventions should be investigated.

\section{Conclusions}

Prescription drug abuse is likely to continue fueling the opioid crisis. The objectives of this study were to increase our understanding and knowledge about PDA and stigma among the general public in the United States with the hope of reducing the degree to which PDA contributes to the crisis. To achieve these objectives, we administered a randomized nation-wide survey of the general population in the United States. Our findings revealed the following. First, those who selfidentified having PDA issues were less likely to correctly identify the condition, and more likely to demonstrate 
stigma. In addition, males are much less likely to identify PDA than females. Younger people were also less likely to correctly identify PDA. In general, males and younger people were also more likely to exhibit stigma. These findings can be used to improve educational efforts in the prevention arena. Given that presence of mental health providers seemed to present an inverse relationship to desired conditions, enlisting these professionals in education campaigns might be a cost-effective mechanism for progress in combating this public health menace. As with any intervention, increased engagement with mental health providers should be evaluated for efficacy.

\section{Abbreviations}

DEA: Drug Enforcement Administration; MAT: Medication-assisted treatment; OAT: Opioid agonist treatment; PDA: Prescription drug abuse; SAMHSA: Substance Abuse and Mental Health Services Administration; USDA: United States Department of Agriculture

\section{Acknowledgements}

Will Dyar provided assistance in data analysis.

\section{Authors' contributions}

RS participated in the survey design, implemented the survey in contact with the survey company, conducted the analysis, and wrote the first draft of the paper and edited the paper. SL wrote the grant proposal that funded this research, assisted with survey design, produced a template that was followed for the preliminary analysis and participated in editing the text. MS assisted with questionnaire design, provided guidance on the approach used in the empirical analysis, and contributed to the writing and editing of the manuscript. BG supported the development of the questionnaire, contributed to the writing of the manuscript, and assisted with editing of the manuscript. DA assisted in the development of the grant proposal and contributed to the writing and editing of the manuscript. All Authors read and approved the final manuscript.

\section{Funding}

The Substance Abuse and Mental Health Services Administration (SAMSHA) provided funding for the survey. The United States Department of Agriculture's National Institute of Food and Agriculture (USDA/NIFA) provided administrative services for the SAMSHA funds. This work is/was supported by the USDA/NIFA, Hatch project 1014691. None of the funding sources exerted any control over the substance of the questions or interpretation of the results.

\section{Availability of data and materials}

The datasets used and/or analyzed during the current study are available from the corresponding author on reasonable request.

\section{Ethics approval and consent to participate}

This study received ethics and consent approval on October 1, 2014 by Michigan State University Human Research Protection Program IRB board. All participants gave written informed consent via reading a written consent statement and clicking "I Agree" before being allowed to take the online survey.

\section{Consent for publication}

Not applicable.

\section{Competing interests}

The authors declare that they have no competing interests.

\section{Author details}

'Department of Agricultural, Food and Resource Economics, Michigan State University, East Lansing, MI 48824, USA. ${ }^{2}$ Department of Agricultural, Food and Resource Economics, Michigan State University, East Lansing, Ml 48824,
USA. ${ }^{3}$ Department of Agricultural, Food and Resource Economics \& Economics, Michigan State University, East Lansing, Ml 48824, USA. ${ }^{4}$ JG Research \& Evaluation, 2103 Bridger Drive, Suite 1, Bozeman, MT 59715, USA. ${ }^{5}$ Western Rural Development Center, Utah State University, 4880 Old Main Hill, Logan, UT 84322, USA.

Received: 15 January 2020 Accepted: 5 June 2020

Published online: 22 June 2020

\section{References}

1. Rudd RA. Increases in drug and opioid-involved overdose deaths-United States, 2010-2015. Morb Mortal Wkly Rep. 2016;65:1445-52.

2. Kennedy-Hendricks A, Barry CL, Gollust SE, Ensminger ME, Chisolm MS, McGinty EE. Social stigma toward persons with prescription opioid use disorder: associations with public support for punitive and public healthoriented policies. Psychiatr Serv. 2017;68:462-9.

3. Winstanley EL, Clark A, Feinberg J, Wilder C. Barriers to implementation of opioid overdose prevention programs in Ohio. Subst Abus. 2016;37(1):42-26.

4. Mayo Clinic, 2019. Diseases and Conditions. Retrieved from https://www. mayoclinic.org/diseases-conditions/drug-addiction/symptoms-causes/syc-2 0365112.

5. Griffiths KM, Christensen H, Jorm AF. Predictors of depression stigma. BMC Psychiatry. 2008;8:25. https://doi.org/10.1186/1471-244X-8-25.

6. Levy B, Spelke B, Paulozzi L, Bell JM, Nolte KB, Lathrop S, Sugerman DE, Landen M. Recognition and response to opioid overdose deaths-New Mexico, 2012. Drug Alcohol Dependence. 2016;1(167):29-35.

7. Goodyear K, Haas-Koffler CL, Havanne D. Opioid use and stigma: the role of gender, language and precipitating events. Drug Alcohol Depend. 2018;185: 339-46.

8. Blanco C, Iza M, Schwartz RP, Rafful C, Wang S, Olfson M. Probability and predictors of treatment-seeking for prescription opioid use disorders: a national study. Drug Alcohol Dependence. 2013;131(0):143-8.

9. Barry CL, McGinty EE, Pescosolido BA, Goldman HH. Stigma, discrimination, treatment effectiveness and policy: public views about drug addiction and mental illness. Psychiatr Serv. 2014;65(10):1269-72.

10. Schaffner B. "Polling: innovations in survey research." in New Directions in Campaigns and Elections, vol. 3. Boca Raton: Taylor and Francis; 2011. p. 59-78.

11. Jorm AF, Korten AE, Jacomb PA, Christensen H, Rodgers B, Pollitt P. Mental health literacy: a survey of the public's ability to recognise mental disorders and their beliefs about the effectiveness of treatment. Med J Aust. 1997; 166(4):182-6.

12. Cerdá M, Wall M, Keyes KM, Galea S, Hasin D. Medical marijuana laws in 50 states: investigating the relationship between state legalization of medical marijuana and marijuana use, abuse and dependence. Drug Alcohol Depend. 2012;120(1):22-7.

13. Governing. State marijuana laws in 2017 map. 2017. Accessed 7 Nov 2017 at http://www.governing.com/gov-data/state-marijuana-laws-map-medicalrecreational.html.

14. Aldrich JH, Nelson FD. Linear probability, logit, and probit models. Thousand Oaks: Sage; 1984

15. SAMHSA. Center for Behavioral Health Statistics and Quality. In: 2015 National survey on drug use and health: detailed tables. Rockville: Substance Abuse and Mental Health Services Administration; 2016.

16. Fergusson DM, Boden JM, Horwood $\amalg$. Tests of causal links between alcohol Abuse or dependence and major depression. Arch Gen Psychiatry. 2009;66(3):260. https://doi.org/10.1001/archgenpsychiatry.2008.543.

17. Grant BF. Comorbidity between DSM-IV drug use disorders and major depression: results of a national survey of adults. J Subst Abus. 1995;7(4): 481-97. https://doi.org/10.1016/0899-3289(95)90017-9.

\section{Publisher's Note}

Springer Nature remains neutral with regard to jurisdictional claims in published maps and institutional affiliations. 